INTERVENTIONAL CARDIOLOGY AND SURGERY

\title{
Superiority of sirolimus eluting stent compared with intracoronary $\beta$ radiation for treatment of in-stent restenosis: a matched comparison
}

\author{
E lofina, P W Radke, P Skurzewski, P K Haager, R Blindt, K-C Koch, P Hanrath, J vom \\ Dahl, R Hoffmann
}

See end of article for authors' affiliations

Correspondence to: Dr Rainer Hoffmann, Medical Clinic I, University RWTH Aachen,

Pauwelsstraße 30, 52057

Aachen, Germany;

RHoffmann@ukaachen.de

Accepted

24 November 2004

Published Online First

29 March 2005

Objective: To compare acute and follow up clinical and angiographic results after treatment of in-stent restenosis (ISR) by sirolimus eluting stents (SES) with results obtained after intracoronary radiation therapy (IRT).

Design: Matched pair analysis.

Methods: 62 consecutive ISR lesions ( $<30 \mathrm{~mm}$ lesion length, reference diameter $<3.5 \mathrm{~mm}$ ) in 62 patients were treated with SES. From a database of 174 lesions ( $n=141$ patients) treated for ISR by intracoronary $\beta$ radiation, 62 lesions (62 patients) were pair matched with the SES group for diabetes mellitus, lesion length, vessel size, and pattern of ISR. Six month angiographic and 12 month clinical follow up results were obtained.

Results: Baseline clinical and angiographic characteristics were similar between the groups (not significant). SES implantation resulted in significantly lower postprocedural in-lesion diameter stenosis than did IRT (mean (SD) 14.2 (9.5)\% v 21.1 (10.6)\%, p = 0.001), significantly higher minimum lumen diameter at follow up (1.91 (0.58) v $1.55(0.72) \mathrm{mm}, \mathrm{p}=0.005)$, and a higher net gain (1.16 (0.55) $v$ $0.77(0.70) \mathrm{mm}, \mathrm{p}=0.002)$. Angiographic binary in-lesion restenosis rate at six months was $11 \%$ in the SES group and $29 \%$ in the IRT group $(p=0.046$ ). In 16 ISR lesions SES were used after failed IRT and in 46 lesions for first time ISR. In-lesion late loss was higher after use of SES for failed IRT than after use of SES for first time ISR $(0.61(0.67) \mathrm{mm} v 0.24(0.41) \mathrm{mm}, \mathrm{p}=0.018)$. In a multivariate analysis prior failed IRT was the only independent predictor for recurrent restenosis after SES for ISR ( $p=0.052$, odds ratio 5.8). Six patients $(10 \%)$ in the SES group and 17 patients $(27 \%)$ in the IRT group underwent target lesion revascularisation during the 12 months of follow up ( $p=0.022$ ).

Conclusions: In this non-randomised matched cohort SES achieved acute and follow up results superior to IRT for treatment of ISR even if cases of failed IRT are included. Failed IRT is a predictor of impaired SES effectiveness.

$\mathrm{T}$ he treatment of in-stent restenosis (ISR) remains one of the most challenging problems in interventional cardiology. Intracoronary radiation therapy (IRT) for ISR lesions is the only approved treatment modality to effectively reduce the rate of recurrent restenosis. ${ }^{12}$ However, IRT is hampered by some potential side effects, but mostly by the complex set up it requires. ${ }^{3-5}$ The introduction of drug eluting stents (DES) has significantly reduced the incidence of ISR as compared with bare metal stents in de novo lesions. ${ }^{6-10}$ While the use of DES for treatment of ISR appears to be attractive, the effectiveness of DES in comparison with IRT for treatment of ISR is not well defined.

With the increasing use of IRT for treatment of ISR, the number of patients with failed IRT has also increased. Recurrent coronary interventions including repeat IRT have been associated with unsatisfactory results. ${ }^{11}{ }^{12}$ Use of DES may provide a new option for these patients.

This study aimed at comparing the acute procedural, six month angiographic, and one year clinical follow up results after treatment of diffuse ISR by sirolimus eluting stents (SES) with results after intracoronary $\beta$ radiation therapy (brachytherapy) in a matched pair analysis.

\section{METHODS}

\section{Patients and lesions}

We enrolled 124 patients with symptomatic ISR lesions (>50\% diameter stenosis) in a native coronary vessel treated by either SES or IRT at the University Hospital Aachen or the Maria-Hilf Hospital Mönchengladbach. At both institutions follow up angiography was performed routinely after treatment of complex ISR lesions requiring SES or IRT.

Sixty two consecutive ISR lesions $(<30 \mathrm{~mm}$ lesion length, reference diameter $<3.5 \mathrm{~mm}$ ) in 62 patients were treated with SES between July 2002 and June 2003 and were entered into a prospective registry. Follow up angiography at an average of 6.3 (1.2) months was available for 53 (85\%) lesions and 12 month clinical follow up was obtained for all 62 patients.

The control group consisting of 62 lesions in 62 patients treated with IRT was recruited from a prospective registry of 141 consecutive patients ( 174 lesions) undergoing $\beta$ radiation therapy for ISR between April 2000 and July 2002 at the University Hospital Aachen. Patients and lesions were matched with the SES group considering the following parameters in sequential selection: diabetes; reference vessel diameter $( \pm 0.2 \mathrm{~mm})$; lesion length $( \pm 2.0 \mathrm{~mm})$; and pattern of ISR according to the classification Mehran et al. ${ }^{13}$ Only one lesion per patient was included in the matching process. For matching purposes all other clinical and

Abbreviations: DES, drug eluting stents; IRT, intracoronary radiation therapy; ISR, in-stent restenosis; MACE, major adverse cardiac event; $M L D$, minimum lumen diameter; SES, sirolimus eluting stents; TLR, target lesion revascularisation 
angiographic variables were blinded. Of the 62 patients in the IRT group comprising the control group, $56(90 \%)$ underwent angiographic follow up at an average of 6.4 (1.5) months; all patients attended clinical follow up at 12 months.

\section{Procedure}

Heparin was administered during the procedure according to standard practice. Aspirin (100 mg/day) and clopidogrel (300 mg loading dose) were started before the procedure. After the procedure, clopidogrel $(75 \mathrm{mg} /$ day $)$ was administered for six months in the SES group and for 12 months in the IRT group in addition to aspirin.

Among lesions treated with SES, 51\% (32 patients) were stented directly. In case of predilatation before placement of a SES a second wire was placed within the vessel to prevent balloon slippage within the restenotic lesion. The vessel was predilated with a balloon $0.5 \mathrm{~mm}$ smaller than the subsequently implanted stent. Implantation of an SES with a length longer than the initial balloon length was encouraged. The sirolimus eluting Cypher stent $\left(140 \mu \mathrm{g}\right.$ sirolimus $/ \mathrm{cm}^{2}$ metal surface area; Cordis) was available in lengths of 8,13 , 18 , and $28 \mathrm{~mm}$ and diameters of $2.5,2.75,3.0$, and $3.5 \mathrm{~mm}$.

In the IRT group balloon angioplasty was the method used to enlarge the lumen. A second wire was placed within the vessel to prevent balloon slippage within the restenotic lesion. Additional stents were implanted before IRT only in case of dissection or remaining stenosis. For IRT a 5 French delivery catheter and a $60 \mathrm{~mm}$ source train of strontium-90 seeds (non-centred $\beta$ emitter, ${ }^{90} \mathrm{Sr}$; Novoste Europe SA/NV Brussels, Belgium) was used.

\section{In-hospital and 12 month clinical follow up}

Procedural success was defined as a $<30 \%$ final diameter stenosis in the treated lesion and the absence of major clinical complications (in-hospital death, Q wave myocardial infarction, or emergency coronary bypass surgery). All patients were monitored for 12 months after the procedure for any major adverse cardiac event (MACE), defined as death, myocardial infarction, or need for repeat target lesion revascularisation (TLR). Baseline clinical demographics, inhospital complications, and the occurrence of death, myocardial infarction, and repeat revascularisation during follow up were verified by an independent hospital chart review and source documentation.

\section{Quantitative coronary angiography}

ISR was classified according to the geographic distribution of intimal hyperplasia in reference to the implanted stent as a focal $(\leqslant 10 \mathrm{~mm}$ in length) lesion or diffuse intrastent $(>10 \mathrm{~mm}$ within the stent), diffuse proliferative

Table 1 Baseline clinical characteristics by type of treatment

\begin{tabular}{llll}
\hline & IRT (n=62) & SES (n=62) & p Value \\
\hline Men & $48(77 \%)$ & $43(69 \%)$ & 0.419 \\
Age (years) & $62(11)$ & $61(10)$ & 0.785 \\
Previous MI & $31(50 \%)$ & $23(37 \%)$ & 0.206 \\
Diabetes mellitus & $12(19 \%)$ & $12(19 \%)$ & 1.000 \\
Arterial hypertension* & $43(69 \%)$ & $53(85 \%)$ & 0.055 \\
Hyperlipidaemiat & $56(90 \%)$ & $55(90 \%)$ & 1.000 \\
Obesity & $33(53 \%)$ & $30(48 \%)$ & 0.723 \\
Smoking & $32(52 \%)$ & $29(46 \%)$ & 0.723 \\
Multivessel disease & $36(58 \%)$ & $31(50 \%)$ & 0.475 \\
History of ACVB & $7(11 \%)$ & $7(11 \%)$ & 1.000 \\
\hline
\end{tabular}

Data are mean (SD) or number (\%).

*Arterial pressure $>160 / 90 \mathrm{~mm} \mathrm{Hg}$ or medically treated; †serum cholesterol $>240 \mathrm{mg} / \mathrm{l}$ or medically treated.

$A C V B$, aortocoronary venous bypass; IRT, intracoronary radiation therapy; MI, myocardial infarction; SES, sirolimus eluting stent.
(> $10 \mathrm{~mm}$ extending outside the stent), or occluded ISR. ${ }^{13}$ Quantitative angiography was analysed at an independent core laboratory of the University Aachen by an investigator blinded to clinical data with a validated quantitative angiographic system (CAAS II System, Pie Medical, Maastricht, the Netherlands) with the contrast filled catheter as the calibration standard.

Quantitative measurements were reference diameter, lesion length, and minimum lumen diameter (MLD) in the lesion (defined as the in-stent segment plus proximal and distal $5 \mathrm{~mm}$ edge segments) and in the stent (without adjacent edge segment) before and after the procedure and at follow up. Late loss (defined as the reduction in MLD from immediately after the procedure to MLD at six months' follow up), acute gain (defined as the increase in MLD immediately after percutaneous transluminal coronary angioplasty), net gain (the difference between the acute gain and late loss), and loss index (the ratio of late loss to acute gain) were calculated. The lesion was described as ostial when it was within $3 \mathrm{~mm}$ of the coronary ostia.

\section{Statistical analysis}

Data were analysed by SPSS software (SPSS Inc, Chicago, Illinois, USA). Categorical data were presented as frequencies and compared by the Pearson $\chi^{2}$ test. Continuous data were presented as mean (SD) and compared by Student's $t$ test or analysis of variance as appropriate. Multivariate analysis to identify predictors for recurrent restenosis after SES considered as parameters the reference vessel diameter, lesion length, postinterventional MLD, diabetes mellitus, lesion location in the left anterior descending artery, and use of SES after failed prior IRT. Follow up TLR events were analysed by actuarial methods and Kaplan-Meier curves were constructed. The choice of treatment modality on recurrent TLR was evaluated with the log rank test. A probability value of $\mathrm{p}<0.05$ was considered significant.

\section{RESULTS}

\section{Baseline characteristics}

In addition to prevalence of diabetes mellitus other baseline clinical characteristics were similar between the two treatment groups (table 1). Groups were also similar with regard to ISR lesion characteristics (table 2).

SES were used in 16 lesions after failed IRT and in 46 lesions for first time ISR. Vascular brachytherapy was used in eight lesions after failed IRT and in 54 lesions for first time ISR.

\section{Procedural data}

The procedure was successful in all patients of the SES group. Thirty lesions $(48 \%)$ were predilated. Two lesions were treated with two overlapping stents. Mean total stent length was $15.9(4.9) \mathrm{mm}$. In three lesions high pressure postdilatation at 16 atm was used because of a suboptimal result.

Table 2 Lesion characteristics

\begin{tabular}{llll}
\hline & IRT $(\mathbf{n}=62)$ & SES $(\mathbf{n = 6 2 )}$ & $\mathbf{p}$ Value \\
\hline Lesion location & $33(53.2 \%)$ & $29(46.8 \%)$ & 0.592 \\
LAD & $21(33.9 \%)$ & $27(43.5 \%)$ & 0.361 \\
RCA & $8(12.9)$ & $6(9.7 \%)$ & 0.781 \\
LCx & & & \\
Pattern of ISR & $20(32.3 \%)$ & $20(32.3 \%)$ & 1.000 \\
Focal (I) & $25(40.2 \%)$ & $21(33.9 \%)$ & 0.629 \\
Diffuse intrastent (II) & $13(21.0 \%)$ & $15(24.2 \%)$ & 0.837 \\
Diffuse proliferative (III) & $4(6.5 \%)$ & $6(9.7 \%)$ & 0.767 \\
Total occlusion (IV) & 4 & \\
\hline ISR, in-stent restenosis; LAD, left anterior descending coronary artery; \\
LCx, left circumflex artery; RCA, right coronary artery.
\end{tabular}




\begin{tabular}{|c|c|c|c|}
\hline & IRT $(n=56)$ & SES $(n=53)$ & p Value \\
\hline \multicolumn{4}{|l|}{ Preprocedural data } \\
\hline Reference diameter $(\mathrm{mm})$ & $2.61(0.39)$ & $2.57(0.35)$ & 0.557 \\
\hline$M L D(m m)$ & $0.70(0.30)$ & $0.68(0.36)$ & 0.789 \\
\hline Diameter stenosis (\%) & $73.0(12.0)$ & $73.2(13.7)$ & 0.944 \\
\hline Lesion length $(\mathrm{mm})$ & $12.17(5.07)$ & $12.08(5.20)$ & 0.922 \\
\hline \multicolumn{4}{|l|}{ Postprocedural data } \\
\hline Reference diameter $(\mathrm{mm})$ & $2.68(0.45)$ & $2.57(0.35)$ & 0.147 \\
\hline MLD in-stent $(\mathrm{mm})$ & $2.12(0.39)$ & $2.43(0.27)$ & $<0.001$ \\
\hline MLD in-lesion (mm) & $2.06(0.39)$ & $2.20(0.33)$ & 0.060 \\
\hline Diameter stenosis in-stent (\%) & $20.4(11.3)$ & $5.0(8.7)$ & $<0.001$ \\
\hline \multirow{2}{*}{\multicolumn{4}{|c|}{ Follow up data }} \\
\hline & & & \\
\hline Reference diameter $(\mathrm{mm})$ & $2.54(0.42)$ & $2.51(0.34)$ & 0.656 \\
\hline MLD in-stent (mm) & $1.60(0.70)$ & $2.14(0.54)$ & $<0.001$ \\
\hline MLD in-lesion (mm) & $1.55(0.72)$ & $1.91(0.58)$ & 0.005 \\
\hline Diameter stenosis in-stent (\%) & $37.4(24.5)$ & $15.3(19.9)$ & $<0.001$ \\
\hline Diameter stenosis in-lesion (\%) & $40.7(25.5)$ & $23.4(22.5)$ & 0.001 \\
\hline Restenosis in-lesion & $16(29 \%)$ & $6(11 \%)$ & 0.046 \\
\hline \multicolumn{4}{|l|}{ Change in MLD } \\
\hline Acute gain in-stent (mm) & $1.42(0.46)$ & $1.75(0.43)$ & $<0.001$ \\
\hline Acute gain in-lesion $(\mathrm{mm})$ & $1.37(0.46)$ & $1.52(0.42)$ & 0.084 \\
\hline Late loss in-stent (mm) & $0.57(0.64)$ & $0.30(0.49)$ & 0.017 \\
\hline Late loss in-lesion (mm) & $0.60(0.67)$ & $0.35(0.53)$ & 0.039 \\
\hline Net gain in-lesion (mm) & $0.77(0.70)$ & $1.16(0.55)$ & 0.002 \\
\hline Loss index in-stent & $0.42(0.60)$ & $0.17(0.24)$ & 0.006 \\
\hline Loss index in-lesion & $0.46(0.63)$ & $0.22(0.29)$ & 0.013 \\
\hline
\end{tabular}

In the IRT group nine lesions (14.5\%) were treated with additional bare metal stents at the stent margins before IRT due to dissection or remaining stenosis. The mean radiation dose was 21.1 (3.1) Gy at a distance of $2 \mathrm{~mm}$ from the radiation source (range 16.0-25.3 Gy). The dwell time was 228 (45) seconds. Two lesions were treated with dilatation after IRT due to recoil in stent.

\section{Angiographic data}

The groups were well matched for restenosis lesion length and reference vessel diameter before intervention as well as other baseline angiographic characteristics. Table 3 summarises quantitative angiographic results for the patients with angiographic follow up. SES implantation resulted in significantly greater in-stent MLD $(2.43 \quad(0.27) \quad v \quad 2.12$ $(0.39) \mathrm{mm}, \mathrm{p}<0.001)$ and lower postprocedural diameter stenosis $(5.0(8.7) \% v 20.4(11.3) \%, \mathrm{p}<0.001)$ than in the IRT group due to a greater acute gain.

At six month angiographic follow up in-stent and in-lesion late loss results for the SES group compared with the IRT group were $0.30(0.49)$ versus $0.57(0.64) \mathrm{mm}(\mathrm{p}=0.017)$ and $0.35(0.53)$ versus $0.60 \quad(0.67) \mathrm{mm}$, respectively $(\mathrm{p}=0.039)$. The greater acute gain in combination with the smaller late loss in the SES group resulted in an even greater difference in net gain between the SES and IRT groups at follow up. Subsequently, in-stent and in-lesion MLDs at follow up were much larger and diameter stenosis was smaller after SES than in the IRT group (table 3, fig 1A). At six months binary in-lesion restenosis was diagnosed in six patients $(11 \%)$ after SES implantation and in 16 patients $(29 \%)$ after IRT $(\mathrm{p}=0.046)$.

Considering only patients treated for first time ISR, angiographic follow up found 37 lesions in the SES group and 48 lesions in the IRT group. Superior results remained for these SES lesions compared with the IRT lesions regarding late loss $(0.25 \quad(0.41) \quad v \quad 0.60 \quad(0.67) \mathrm{mm}$, respectively, $\mathrm{p}=0.005)$ and in-lesion MLD at follow up (2.03 (0.47) $v$ $1.53(0.64) \mathrm{mm}$, respectively, $\mathrm{p}<0.001$ ) (fig $1 \mathrm{~B}$ ).
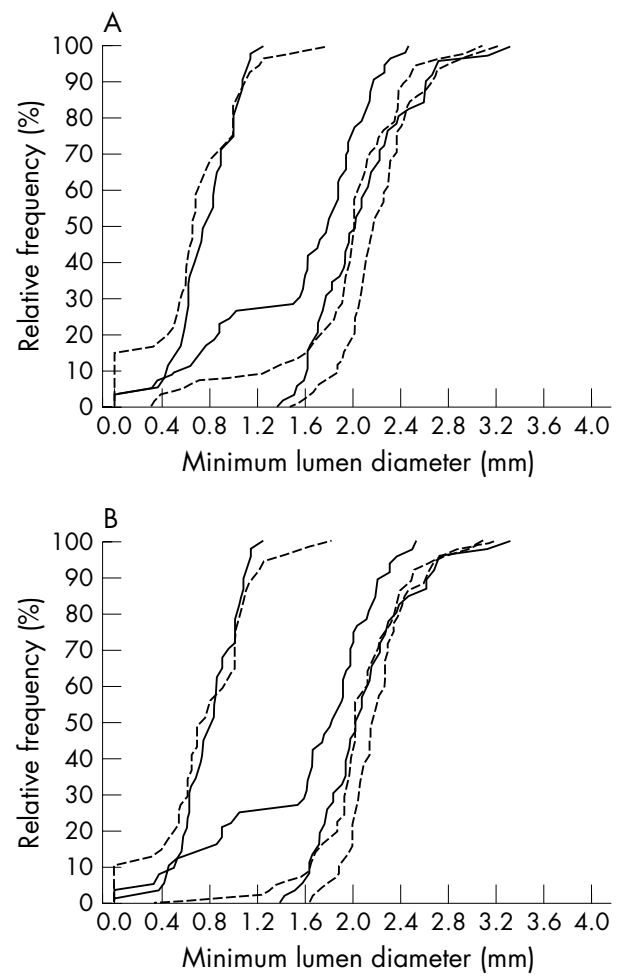

Figure 1 Preinterventional, postinterventional, and follow up cumulative distribution curves of in-lesion minimum lumen diameter of in-stent restenosis lesions treated either by intracoronary radiation therapy (solid lines) or sirolimus eluting stents (dotted line). (A) Results of all patients with angiographic follow up. (B) Results only of patients treated for first time in-stent restenosis.

\section{Impact of prior failed vascular brachytherapy}

Angiographic follow up was available for 16 lesions after SES for failed IRT and for 37 lesions after SES for first time ISR. 
Table 4 SES for failed vascular brachytherapy versus SES for first time in-stent restenosis

\begin{tabular}{|c|c|c|c|}
\hline & $\begin{array}{l}\text { SES for the first } \\
\text { time ISR }(n=37)\end{array}$ & $\begin{array}{l}\text { SES for failed } \\
\text { IRT }(n=16)\end{array}$ & p Value \\
\hline \multicolumn{4}{|l|}{ Preprocedural data } \\
\hline Reference (mm) & $2.59(0.39)$ & $2.51(0.23)$ & 0.409 \\
\hline MLD (mm) & $0.74(0.36)$ & $0.54(0.33)$ & 0.073 \\
\hline Lesion length $(\mathrm{mm})$ & $12.01(4.81)$ & $12.25(6.19)$ & 0.878 \\
\hline \multicolumn{4}{|l|}{ Follow up data } \\
\hline Late loss (mm) & $0.24(0.41)$ & $0.61(0.67)$ & 0.018 \\
\hline Restenosis rate) & $2(5.4 \%)$ & $4(25.0 \%)$ & 0.115 \\
\hline TLR at 12 months & $1(3 \%)$ & $5(31 \%)$ & 0.012 \\
\hline
\end{tabular}

Baseline angiographic parameters were comparable between the SES for failed IRT group and the SES for first time ISR group with regard to reference diameter $(2.51$ (0.23) $v 2.59$ (0.39) $\mathrm{mm}$, respectively, $\mathrm{p}=0.409)$ and lesion length ( 12.3 (6.2) v $12.0(4.8) \mathrm{mm}$, respectively, $p=0.878)$. Other angiographic and clinical parameters were also comparable. In-lesion late loss was higher after SES for failed IRT than after SES for first time ISR (0.61 (0.67) $v 0.24(0.41) \mathrm{mm}$, respectively, $\mathrm{p}=0.018$ ). Similarly, the restenosis rate tended to be higher after SES for failed IRT than after SES for first time ISR $(25.0 \% \vee 5.4 \%$, respectively, $\mathrm{p}=0.118)$.

Among the IRT group angiographic follow up was available for eight lesions treated with IRT after failed IRT and for 46 lesions treated with IRT for first time ISR. In-lesion late loss was not significantly different between lesions treated after failed IRT and lesions treated for first time ISR $(0.70(0.63) v$ $0.60(0.67) \mathrm{mm}$, respectively, $\mathrm{p}=0.711)$.
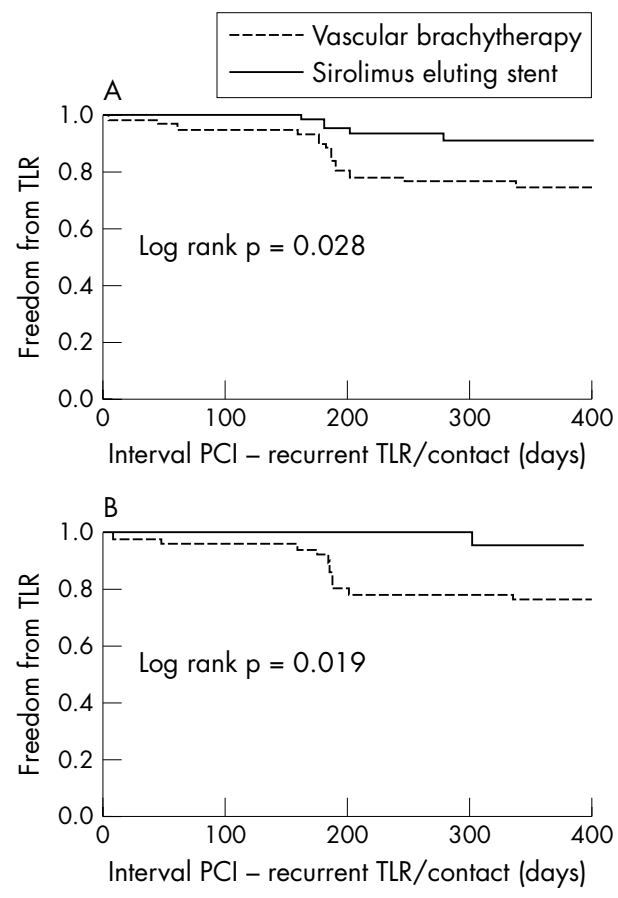

Figure 2 Cumulative target lesion revascularisation (TLR) -free survival of patients with in-stent restenosis treated with either sirolimus eluting stents or intracoronary radiation therapy at percutaneous coronary intervention (PCI). (A) Results of all patients. (B) Results only of patients treated for first time in-stent restenosis.

\section{Predictors of recurrent restenosis after SES for} treatment of ISR

In five patients of the SES group found to have recurrent restenosis at angiographic follow up the lesion was treated for failed IRT. In one lesion there was focal restenosis at the hinge point of a vessel with an almost $90^{\circ}$ angulation. In a multivariate analysis failed prior IRT was the only independent predictor for recurrent restenosis after SES for ISR $(\mathrm{p}=0.052$, odds ratio 5.8).

\section{Clinical outcome}

Complete 12 month clinical follow up was obtained for all patients. One patient in the IRT group (1.6\%) had subacute stent thrombosis, which was successfully treated with repeat percutaneous transluminal coronary angioplasty. Sixteen additional MACE (26\%) in the IRT group during the 12 month follow up were due to repeat TLR for ISR. Five patients underwent repeated brachytherapy, a DES was implanted in seven patients, and four patients underwent bypass surgery. Six $(10 \%)$ patients in the SES group underwent TLR during the 12 months of follow up. Three patients received brachytherapy, two patients had an additional SES implanted for focal lesions, and one patient underwent bypass surgery. One additional patient died after six months without prior repeat angiography. The patient had severe three vessel disease. The cause of death was not defined. Thus, the MACE rates at 12 months were $27 \%$ ( 17 patients) versus $11 \%$ (seven patients) $(p=0.043)$ in the IRT and SES groups, respectively. This was driven by the difference in the TLR rate $(27 \% v 10 \%, \mathrm{p}=0.022)$. Considering only patients treated for first time ISR the difference in TLR rate at 12 months was even greater between the two treatment groups (table 4). Kaplan-Meier survival analysis also showed significant differences in TLR-free survival curves between SES and IRT treated patients, irrespective of whether patients with prior failed IRT were included (fig 2A) or excluded (fig 2B).

\section{DISCUSSION}

The results of this study indicate, firstly, favourable acute and follow up angiographic results and a low rate of repeat revascularisation procedures with the use of SES for treatment of ISR; secondly, superior angiographic and clinical follow up results after SES compared with IRT for treatment of ISR; and thirdly, impaired effectiveness of SES for treatment of ISR after failed IRT.

\section{Treatment modalities for ISR}

Whereas treatment modalities for ISR based merely on mechanical dilatation or tissue ablation are associated with an unacceptable rate of treatment failures, ${ }^{14-16}$ the use of IRT to treat ISR has proved in several multicentre studies to reduce recurrent ISR during short term follow up by 40$70 \% .{ }^{17}$ However, acute procedural results after IRT are inferior to results after implantation of the stent at the first index procedure; lumen loss after IRT was reported to be still between $0.38-0.64 \mathrm{~mm}$ with either $\gamma$ or $\beta$ radiation. ${ }^{17}{ }^{18}$ Recurrent restenosis rates in the range of $22-32 \%$ have been reported after IRT for ISR. ${ }^{17}{ }^{18}$ Furthermore, IRT should be considered a treatment with long term biological implications. The phenomenon of delayed lumen reduction and restenosis has repeatedly been suggested as an additional limitation of this treatment strategy. ${ }^{19} 20$ The late lumen loss of $0.60(0.67) \mathrm{mm}$ at six months' follow up in this study for lesions treated with IRT for first time ISR is consistent with previous studies. 


\section{SES for ISR}

The use of SES has been shown in randomised clinical trials to result in an in-stent lumen loss of -0.01 to $0.20 \mathrm{~mm}$ for de novo coronary lesions. ${ }^{6-10}$ Slightly higher lumen loss ranging from $0.12(0.41)$ to $0.21(0.62) \mathrm{mm}$ has been reported in small registries with the use of SES for ISR lesions. ${ }^{21}{ }^{22}$ In this study in-stent lumen loss in the SES group was 0.30 $(0.49) \mathrm{mm}$ if patients with failed IRT were included and $0.23(0.41) \mathrm{mm}$ if only patients with SES used for first time ISR were analysed. Thus, the results are comparable with those of previous studies on the use of SES for ISR.

It is important to note that not all ISR lesions have a similar risk of recurrence. ${ }^{13}$ This has to be considered if angiographic and clinical follow up results for different treatment modalities for ISR are compared. Most studies analysing the procedural and follow up results of different treatment strategies for ISR were not randomised or matched comparisons. ${ }^{23}$ In this study ISR lesions treated with SES were matched to those treated with IRT considering previously defined predictors of recurrent restenosis.

The results of this study indicate that a significantly greater postprocedural lumen could be obtained in the SES group than in the IRT group due to a larger acute lumen gain. This finding relates to previous studies that have shown superior acute lumen gain with the in-stent technique compared with balloon angioplasty for ISR and to a recent report on postprocedural angiographic results after SES versus IRT. ${ }^{23}{ }^{24}$ Subsequently, the lumen loss in the SES group was smaller than in the group treated with IRT. Thus, implantation of SES appears to combine the beneficial effect of a greater acute gain and a reduced late loss as compared with IRT. Improved lumen dimensions, greater net gain, and a lower restenosis rate at the six month follow up angiography are the result. As a consequence the TLR rate after SES compared favourably during the study observation period with that of the matched IRT group.

Restenosis after SES for ISR was focal in four of the observed six cases of recurrent restenosis. This finding is consistent with previous reports, which showed that recurrent restenotic lesions after implantation of SES in de novo lesions tend to be focal. ${ }^{25}{ }^{26}$ It may imply that recurrent restenosis after use of SES for ISR will be manageable by further percutaneous coronary intervention. However, the best treatment after failed DES for ISR may be an even more delicate problem than treatment after failed vascular brachytherapy for ISR.

\section{SES for ISR after failed vascular brachytherapy}

Despite the effectiveness of IRT in reducing recurrence of ISR, short term failure occurs in $25-30 \%$ of patients. ${ }^{151718}$ These patients are in a high risk population with limited treatment options. Repeat percutaneous coronary intervention in patients with failed IRT has been applied but has been associated with high MACE rates, mainly due to the need for recurrent TLR. ${ }^{11}$ Even readministration of IRT has also been linked with a frequent need for further TLR. ${ }^{27}$ In this study eight lesions in the IRT group were treated for failed prior IRT. These lesions were characterised by a high late loss. Use of DES for treatment of lesions with failed IRT has also been suggested. Saia et $a^{28}$ reported a rate of recurrent angiographic restenosis of $40 \%$ in a series of 10 patients treated with SES after failed IRT for ISR. In SECURE (sirolimuseluting BX velocity balloon-expandable stent in a compassionate use registry), with angiographic follow up of 58 lesions, restenosis was observed in $38 \%{ }^{29}$

In the present study late loss was significantly higher in patients with SES for failed IRT than in patients with use of SES for first time ISR. TLR recurred in $31 \%$ of patients with failed IRT as compared with $3 \%$ of patients with SES implanted for a first ISR. Furthermore, failed IRT was the only independent predictor for recurrent restenosis after use of SES for ISR. Thus, patients with failed IRT certainly define a population that is at risk of developing recurrent restenosis also after use of SES.

\section{Limitations}

This was not a randomised study. However, both study groups were recruited from prospective registries. Furthermore, previous studies on ISR have reported lesion length, reference diameter, pattern of ISR, and presence of diabetes mellitus to be predictors of recurrent restenosis after treatment of ISR. The matched pair analysis of this study controlled these four parameters to result in similar baseline risks. This study included only six month angiographic follow up. However, although evidence is accumulating for subsequent delayed lumen loss and restenosis after IRT-the late catch up phenomenon-resulting in a declined effectiveness of this treatment in comparison with balloon angioplasty, delayed lumen loss after use of SES has not been observed. ${ }^{20}$ Thus, angiographic follow up studies at a later time point are likely to show a further divergence of angiographic results. Still, the subsequent long term outcomes of both treatment strategies will have to be defined. This study did not include routine intravascular ultrasound analysis. Thus, a detailed analysis of vascular responses to both treatment modalities was not possible.

\section{Conclusions}

Treatment of complex ISR by SES results in superior acute and follow up angiographic and clinical outcome to treatment with IRT. DES are likely to become the preferred treatment strategy for patients with diffuse ISR. Prior failed IRT impairs the effectiveness of SES for treatment of ISR.

Ekaterina Iofina received a research grant from the Deutsche Akademische Auslandsdienst (Bonn, Germany).

\section{Authors' affiliations}

E lofina, P W Radke, P K Haager, R Blindt, K-C Koch, P Hanrath, R Hoffmann, Medical Clinic I, University RWTH Aachen, Aachen, Germany

P Skurzewski, J vom Dahl, Medical Clinic II, Maria-Hilf Krankenhaus, Mönchengladbach, Germany

\section{REFERENCES}

1 Leon MB, Teirstein PS, Moses JW, et al. Localized intracoronary gammaradiation therapy to inhibit the recurrence of restenosis after stenting. N Engl J Med 2001;344:250-6.

2 Lowe $\mathrm{H}$, Oesterle S, Khachigan L, et al. Coronary in-stent restenosis: current status and future strategies. J Am Coll Cardiol 2002;39:183-93.

3 Waksman R, Bhargava $B$, Mintz $G$, et al. Late total occlusion after intracoronary brachytherapy for patients with in-stent restenosis. J Am Coll Cardiol 2000;36:65-8.

4 Costa MA, Sabate M, van der Giessen WJ, et al. Late coronary occlusion after intracoronary brachytherapy. Circulation 1999;100:789-92.

5 Teirstein PS, Massullo V, Jani S, et al. Three-year clinical and angiographic follow-up after intracoronary radiation: results of a randomised clinical trial. Circulation 2000;101:360-5.

6 Morice M-C, Serruys PW, Soussa JE, et al. A randomized comparison of a sirolimus-eluting stent with a standard stent for coronary revascularization. N Engl J Med 2002;346:1773-80.

7 Schofer J, Schluter M, Gershlick AH, E-SIRIUS Investigators, et al. Sirolimuseluting stents for treatment of patients with long atherosclerotic lesions in small coronary arteries: double-blind, randomised controlled trial (E-SIRIUS). Lancet 2003;362:1093-9.

8 Park SJ, Schim WH, David S, et al. A paclitaxel-eluting stent for the prevention of coronary restenosis. N Engl J Med 2003;348:1537-45.

9 Soussa JE, Costa MA, Abizaid AC, et al. Sustained suppression of neointimal proliferation by sirolimus-eluting stents: one-year angiographic and intravascular ultrasound follow-up. Circulation 2001;104:2007-11.

10 Moses JW, Leon MB, Popma JJ, et al. Sirolimus-eluting stents versus standard stents in patients with stenosis in a native coronary artery. N Engl J Med 2003;349:1315-23.

11 Prpic R, Teirstein P, Reilly J, et al. Long-term outcome of patients treated with repeat percutaneous coronary intervention after failure of gamma- 
brachytherapy for the treatment of in-stent restenosis. Circulation 2002; 106:2340-5.

12 Saia F, Sianos G, Hoye A, et al. Long-term outcome of percutaneous coronary interventions following failed beta-brachytherapy. J Invasive Cardiol 2004; 16:60-4

13 Mehran R, Dangas G, Abizaid AS, et al. Angiographic patterns of in-stent restenosis classification and implications for long-term outcome. Circulation 1999;100:1872-8.

14 Elezi S, Kastrati A, Hadamitzky M, et al. Clinical and angiographic follow-up after balloon angioplasty with provisional stenting for coronary in-stent restenosis. Catheter Cardiovasc Interv 1999;48:151-6.

15 Vom Dahl J, Dietz U, Haager PK, et al. Rotational atherectomy does not reduce recurrent in-stent restenosis: results of the angioplasty versus rotational atherectomy for treatment of diffuse in-stent restenosis trial (ARTIST). Circulation 2002; 105:583-8.

16 Mehran R, Dangas G, Mintz GS, et al. Treatment of in-stent restenosis with excimer laser coronary angioplasty versus rotational atherectomy: comparative mechanisms and results. Circulation 2000;103:2484-9.

17 Waksman R, Raizner AE, Yeung AC, et al. Use of localised intracoronary beta radiation in treatment of in-stent restenosis: the INHIBIT randomised controlled trial. Lancet 2002;359:551-7.

18 Waksman $\mathbf{R}$, Cheneau $E$, Ajani $A E$, et al. Intracoronary radiation therapy improves the clinical and angiographic outcomes of diffuse in-stent restenotic lesions: results of the washington radiation for in-stent restenosis trial for long lesions (Long WRIST) studies. Circulation 2003;107:1744-9.

19 Schiele T, Pöllinger B, Kantlehner R, et al. Evolution of angiographic restenosis rate and late lumen loss after intracoronary beta radiation for in-stent restenotic lesions. Am J Cardiol 2004;93:836-42.
20 Brenner D, Miller R. Long-term efficacy of intracoronary irradiation in inhibiting in-stent restenosis. Circulation 2001;103:1330.

21 Degertekin $\mathrm{M}$, Lemos $\mathrm{P}$, Lee $\mathrm{CH}$, et al. Intravascular ultrasound evaluation after sirolimus eluting stent implantation for de-novo and in-stent restenotic lesions. Eur Heart J 2004;25:32-8.

22 Degertekin M, Regar E, Tanabe K, et al. Sirolimus-eluting stent for the treatment of complex in-stent restenosis: the first clinical experience. J Am Coll Cardiol 2003;41:184-9.

23 Saia F, Lemos $\mathrm{P}$, Hoye $\mathrm{A}$, et al. Clinical outcomes for sirolimus-eluting stent implantation and vascular brachytherapy for the treatment of in-stent restenosis. Catheter Cardiovasc Interv 2004;62:283-8.

24 Alfonso F, Zueco J, Cequier A, et al. A randomized comparison of repeat stenting with balloon angioplasty in patients with in-stent restenosis. J Am Coll Cardiol 2003:42:796-805.

25 Colombo A, Orlic D, Stankovic G, et al. Preliminary observations regarding angiographic pattern of restenosis after rapamycin-eluting stent implantation. Circulation 2003; 107:2178-80.

26 Lemos PA, Saia F, Ligthart JM, et al. Coronary restenosis after sirolimuseluting stent implantation: morphological description and mechanistic analysis from a consecutive series of cases. Circulation 2003; 108:257-60.

27 Waksman $R$, Lew $R$, Ajani $A E$, et al. Repeat intracoronary radiation for recurrent in-stent restenosis in patients who failed intracoronary radiation. Circulation 2003;108:654-6.

28 Saia $F$, Lemos $P$, Sianos $G$, et al. Effectiveness of sirolimus-eluting stent implantation for recurrent in-stent restenosis after brachytherapy. Am J Cardiol 2003;92:200-3.

29 Teirstein PS, Kao J, Bass TA, et al. Use of sirolimus-eluting Bx velocity stent for failed brachytherapy in recurrent in-stent restenosis: results from the SECURE registry. J Am Coll Cardiol 2003;48(suppl A):41

\section{IMAGES IN CARDIOLOGY}

\section{Scimitar syndrome}

$\mathrm{S}$ cimitar syndrome is a rare condition characterised by partial or complete anomalous pulmonary venous drainage to the inferior vena cava. The term derives from the curvilinear shadow created by the anomalous pulmonary vein on the chest radiograph. The shadow extends medially from the lateral superior position of the right lung and increases in calibre as it descends toward the cardiophrenic angle.

An 18 year old man was referred for evaluation of recurrent pleuritis. The chest radiograph showed prominent central pulmonary arteries with normal tapering into the periphery and a typical scimitar shaped shadow in the right lung (panel A, arrows). Magnetic resonance imaging in the transverse plane showed the scimitar vein at the level of its connection with the inferior vena cava, just below the level of the right atrium (panel B: IVC, inferior vena cava; SV, scimitar vein). The coronal plane revealed the entire length of the scimitar vein (panel $\mathrm{C}$ : $\mathrm{AO}$, ascending aorta; LV, left ventricle; MPA, main pulmonary artery; RA, right atrium; RPA, right pulmonary artery; $\mathrm{RV}$, right ventricle). The right lung and airways were of

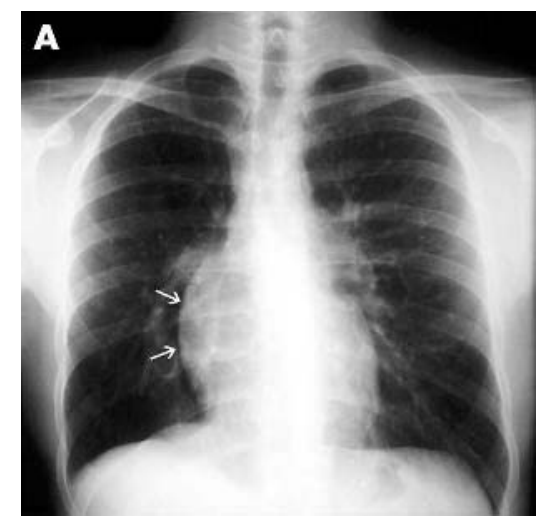

normal size. On both echocardiography and first pass nuclear scan, the presence of a large left to right shunt (Qp/ Qs $=2$ ) was confirmed, caused by the anomalous pulmonary venous drainage through the scimitar vein.

At surgery, a pericardial baffle was created to redirect the blood from the anomalous vein through a surgically created atrial septal defect into the left atrium. Surgically treated scimitar syndrome has an excellent long term prognosis and most patients are asymptomatic.
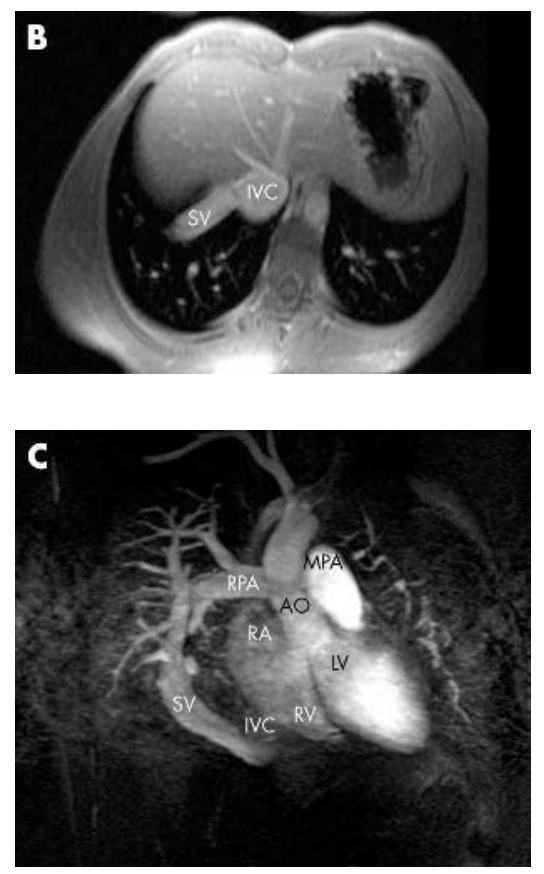

G P Georghiou

B A Vidne

R Hirsch

georgios@clalit.org.il 